larvæ of this kind, or adjacent to them, accumulations of phagocytes are frequently observed. These accumulations appear to depend upon the diffusion into the blood of substances from the destroyed tissues, or, as Pantel suggests, on the diffusion of toxins from bacteria which have penetrated into the body of the caterpillar through the opening made by the parasite. Sometimes the accumulations of phagocytes are very extensive and completely surround the parasite, but they never penetrate into its body, nor is there any good evidence that they impede its development.

The statements just made summarise the data in what may be called cases of natural parasitism. As will be seen, they afford no support for the view that the adaptation of the internal insect parasite to its host consists essentially in the development of substances destined to repel the phagocytes, or in structures designed to afford protection from their attack. To test this point, I carried out several years ago a number of experiments, during which I introduced into the body cavity of living insects sarcophagous or parasitic larvæ, which are never found in the species concerned in Nature. In some of these experiments the parasites introduced into the unfamiliar hosts lived and developed in the normal way, and in that case were never molested by the phagocytes. In other cases they died and the phagocytes gathered around their bodies except when the host was in a very diseased or exhausted condition, but in no case was any accumulation of phagocytes observed around a living parasite. The results of these experiments were confirmed by others, in which the larva of the internal parasite was killed without wounding the host, by blocking up the opening of its respiratory funnel. No accumulation of phagocytes around the parasite larva was observed in such cases so long as it remained alive, but after its death, blood cells began at once to accumulate about it.

It has long been known that phagocytes become extremely abundant during the pupal period and are found during this time migrating into and destroying the degenerating larval tissues, but there is no reason to suppose that this period is especially dangerous for internal parasites, or that they require any protective secretions or structures in order to enable them to survive it. Chalcis Fonscolombei Duf., the parasite of Sarcophagids, which attacks its host during the late larval stage and emerges from the puparia, does not possess any sack. The same thing is true of Alysia manducator Panz., the Braconid parasite of Lucilia sericata Meig. On the other hand, there is no reason to suppose that the trophamnion which occurs in some pupal parasites is a protection against phagocytic attack, for there are many parasites which live within a membrane of this type, but infest their host only during the larval period, as, for example, the polyembryonic Encyrtids.

Finally, the idea that phagocytes break down the tissues of the parasites they attack and that the substance of the latter is built up into the tissues of the host, seems also to be contrary to the facts. The accumulation of phagocytes about the body of a dead parasite appears to continue for a consider. able time, but it is not certain that the phagocytes ever disperse. Dead eggs or larvæ may often be found many months after their death has occurred, surrounded by a dense ball of phagocytes, many cells thick, of which the internal layers show manifest signs of cellular degeneration. Within these balls the dead larvæ disintegrate, but the action of the autolytic enzymes would produce this effect without the intervention of the phagocytes, which do not, so far as I have observed, actually penetrate into the bodies of the parasites.

\footnotetext{
1 E. Metchnikoff, “ Leçons sur la pathologie comparée de l'inflamma-

${ }_{2}^{\text {tion "'. (Paris: Masson, 1892.) }}$ Cuénot, Arch. de Biol., 14, 1er fasc., 1895, and 15, 1897, ParisBr ussels.

3 J. Pantel, La Cellule, 15, 1er fasc., 1898, and 26, 1er fasc., 1910 , Louvain.

W. R. Thompson, Bull. Soc. Zool. France, 40, p. 63; 1915.
M. Caullery, "Le parasitisme et la symbiose". (Paris, Doin, 1922.)
}

\title{
Clerk Maxwell and the Michelson Experiment.
}

W E have received from Mr. Rollo Appleyard, author of "Pioneers of Electrical Communication", a copy of correspondence that he has had with Prof. P. Lenard, of Heidelberg, on the association of Clerk Maxwell with the Michelson experiment. Prof. Lenard suggested that although it is universally acknowledged that Maxwell played an important part in instituting the inquiry, it would be helpful if references could be obtained to Maxwell's own account of his views. Mr. Appleyard accordingly furnished the following particulars, which Prof. Lenard requested might be published in NATURE, in order that full credit might be given to Clerk Maxwell for the part he took in inspiring the Michelson experiment.

At a meeting of the Royal Society on Jan. 6, 1880, Prof. G. Stokes, the secretary, communicated a paper by Prof. Clerk Maxwell, who had recently died; the paper was a letter to Prof. D. P. Todd, who was then Director of the American Ephemeris.
This letter suggested that careful observations of the times of the eclipses of Jupiter's satellites, when Jupiter was in different directions as seen from the earth, might show whether the velocity of light varied in different directions, owing to the motion of the solar system through the ether. Clerk Maxwell admitted that he was not an astronomer, and was doubtful whether the eclipses could be timed with sufficient accuracy to test the suggestion. He thought it would probably be agreed that the only class of observations that would be of sufficient accuracy for the purpose would be the photometric ones that were made at Harvard College Observatory, or others on similar lines. Even with these Prof. R. A. Sampson found puzzling anomalies, due perhaps to changes in the character of Jupiter's surface, which is of a cloudy nature, and apparently subject to variations in its transparency.

Clerk Maxwell had thought that terrestrial ex- 
periments would be useless to solve the problem, owing to the extreme smallness of the quantity to be measured, which is one of the second order. However, his letter led to an article by Prof. A. A. Michelson, which appeared in the American Journal of Science for August 1881, extracts from which are printed below. It will be seen that Michelson refers to Maxwell's suggestion, and notes that the secondorder quantity, which Maxwell had considered too small to determine, is "easily measurable". He then gives an outline of what we now know as the Michelson experiment.

Clerk Maxwell's name therefore deserves mention since apparently his suggestion, though not fruitful in the manner that he hoped, had some effect in bringing about the famous experiment, the result of which laid the foundation of the theory of relativity.

Extract from American Journal of Science, Series (3), Vol. 22, p. 120, August 1881.

Art. XXI.-The Relative Motion of the Earth and the Luminiferous Ether.

By Albert A. Michelson, Master, U.S. Navy.

Let $V$ be the velocity of light.

$v=$ the speed of the earth with respect to the ether.

$D=$ the distance between the two points.

$d=$ the distance through which the earth moves while light travels from one point to another (on the earth's surface).

$d_{1}=$ the distance earth moves while light passes in the opposite direction.

Suppose the direction of the line joining the two points to coincide with the direction of earth's motion and let

$T=$ time required for light to pass from the one point to the other, and

$T_{1}=$ time required for it to pass in the opposite direction. Further, let

$T_{0}=$ time required to perform the journey if the

Then earth were at rest.

$$
T=\frac{D+d}{V}=\frac{d}{v}, \quad \text { and } \quad T_{1}=\frac{D-d}{V}=\frac{d_{1}}{v} .
$$

From these relations we find

whence

$$
d=D \frac{v}{V-v}, \text { and } d_{1}=D \frac{v}{V+v},
$$

$$
\begin{gathered}
T=\frac{D}{V-v} \text { and } T_{1}=\frac{D}{V+v}, \\
T-T_{1}=2 T_{0} \frac{v}{V} \text { nearly, and } \\
v=V \frac{T-T_{1}}{2 T_{0}} .
\end{gathered}
$$

If now it were possible to measure $T-T_{1}$, since $V$ and $T_{0}$ are known, we could find $v$, the velocity of the earth's motion through the ether.

In a letter, published in NATURE shortly after his death [read before the Royal Society on Jan. 6, 1880 ; see Nature, Jan. 29, 1880, p. 314], Clerk Maxwell pointed out that $T-T_{1}$ could be calculated by measuring the velocity of light by means of the eclipses of Jupiter's satellites at periods when that planet lay in different directions from earth ; but that for this purpose the observations of these eclipses must greatly exceed in accuracy those which have thus far been obtained. In the same letter, it was also stated that the reason why such measurements could not be made at the earth's surface was that we have thus far no method for measuring the velocity of light which does not involve the necessity of returning the light over its path, whereby it would lose nearly as much as was gained in going. The difference depending on the square of the ratio of the two velocities, according to Maxwell, is far too small to measure.

The following is intended to show that with a wavelength of yellow light as a standard, the quantityif it exists-is easily measurable. Using the same notation as before, we have-

$$
T=\frac{D}{V-v}, \text { and } T_{1}=\frac{D}{V+v} .
$$

The whole time occupied therefore in going and returning [is]

$$
T+T_{1}=2 D \frac{V}{V^{2}-v^{2}} .
$$

If, however, the light had travelled in a direction at right angles to the earth's motion it would be entirely unaffected, and the time of going and returning would be therefore

$$
2 \frac{D}{V}=2 T_{0}
$$

The difference between the times $T+T_{1}$ and $2 T_{0}$ is

$$
\begin{gathered}
2 D V\left(\frac{1}{V^{2}-v^{2}}-\frac{1}{V^{2}}\right)=\tau, \\
\tau=2 D V \frac{v^{2}}{V^{2}\left(V^{2}-v^{2}\right)} \text { or nearly } 2 T_{0} \frac{v^{2}}{V^{2}} .
\end{gathered}
$$

In the time $\tau$ the light would travel a distance

$$
V \tau=2 V T_{0} \frac{v^{2}}{V^{2}}=2 D_{\bar{V}^{\overline{2}}}^{v^{2}}
$$

That is, the actual distance the light travels in the first case is greater than in the second, by the quantity $2 D_{\overline{V^{2}}}^{v^{2}}$

Considering only the velocity of the earth in its orbit, the ratio

$$
\begin{gathered}
\frac{v}{V}=\frac{1}{10,000} \text { approximately, and } \\
\frac{v^{2}}{\bar{V}^{2}}=\frac{1}{100,000,000} .
\end{gathered}
$$

If $D=1200$ millimetres, or in wave-lengths of light, $2,000,000$, then in terms of the same unit,

$$
2 D \frac{v^{2}}{V^{2}}=\frac{4}{100} \text {. }
$$

If, therefore, an apparatus is so constructed as to permit two pencils of light, which have travelled over paths at right angles to each other, to interfere, the pencil which has travelled in the direction of the earth's motion, will in reality travel $x^{\frac{1}{0} \sigma}$ of a wavelength farther than it would have done were the earth at rest. The other pencil being at right-angles to the motion would not be affected. . . .

In conclusion, I take this opportunity to thank Mr. Graham Bell, who has provided the means for carrying out this work, and Professor Vogel, the Director of the Astrophysikalisches Observatorium [in Potsdam], for his courtesy in placing the resources of the laboratory at my disposal. 